\title{
In vitro zinc protoporphyrin IX formation in different meat sources related to potentially important intrinsic parameters
}

Hannelore De Maere ${ }^{1}$, Sylvie Chollet ${ }^{2}$, Erik Claeys ${ }^{3}$, Chris Michiels ${ }^{4}$, Marlies Govaert $^{1}$, Eveline De Mey ${ }^{1}$, Hubert Paelinck ${ }^{1}$, Ilse Fraeye ${ }^{1^{*}}$

\footnotetext{
${ }^{1}$ Research Group for Technology and Quality of Animal Products, Department $M^{2} S$, member of Leuven Food Science and Nutrition Research Centre (LFoRCe), KU Leuven Technology Campus Ghent, Gebroeders De Smetstraat 1, B-9000 Ghent, Belgium

${ }^{2}$ IICV - Institut Charles Viollette, EA 7394, USC 1281, ISA Lille, Lille F-59000, France
}

${ }^{3}$ UGent - Lanupro Laboratory for Animal Nutrition and Animal Product Quality, Faculty of Bioscience Engineering, Ghent University, Proefhoevestraat 10, 9090 Melle, Belgium;

${ }^{4}$ Centre for Food and Microbial Technology, Department $M^{2} S$, member of Leuven Food Science and Nutrition Research Centre (LFoRCe), KU Leuven, Kasteelpark Arenberg 23 box 2457, B-3001 Leuven, Belgium

*corresponding author: Tel.: +32 926586 10; fax: +32 926587 24;

E-mail address: ilse.fraeye@kuleuven.be

\section{Acknowledgements}

This work was performed with financial support of internal funding of KU Leuven. 


\begin{abstract}
For several years, researchers have studied the formation of zinc protoporphyrin IX in meat, as it is considered to be an important natural colouring agent in dry cured or fermented meat products in the absence of nitrite and/ or nitrate. Until now, however, mainly pork meat is used for these investigations. The goal of this research was to relate in vitro zinc protoporphyrin IX and protoporphyrin IX formation in eight meat sources (chicken, turkey, pork, lamb, beef, veal, horse and porcine liver) to eight intrinsic parameters using Partial Least Squares Regression (PLS) analysis. Significant differences in $\mathrm{pH}$, initial metmyoglobin formation, metmyoglobin reduction ability, total heme, zinc chelatase activity and total iron and zinc concentration between meat sources were found. Water activity, however, was not significantly different between meat sources. Liver tissue and horse meat showed the best ability to form zinc protoporphyrin IX. Formation of protoporphyrin IX was limited in all meat sources. PLS analysis revealed that mainly zinc chelatase activity, followed by total heme, total iron and zinc content, were predominant intrinsic parameters to explain variations in zinc protoporphyrin IX formation. These findings could be important for meat industry in order to establish the production of red coloured nitrite-free meat products.
\end{abstract}

Keywords: zinc chelatase activity; total heme; iron and zinc content; zinc protoporphyrin IX formation 


\section{Introduction}

The heme-biosynthesis pathway in living mammals involves a series of eight enzymatic steps and occurs partly in the cytosol and in the mitochondrial compartments. Ferrochelatase (FECH; EC 4.99.1.1), located in the inner membrane of the mitochondria, catalyzes in the last step the insertion of ferrous iron into protoporphyrin IX (PPIX) to form protoheme (Aijoka et al. 2006). Finally, protoheme (also called heme) is assembled with different heme proteins, e.g. hemoglobin and myoglobin which are responsible for oxygen transport in blood and muscle cells, respectively (Devine and Dikeman 2004; Lindahl 2005). Zinc protoporphyrin IX (Zn(II)PPIX), whereby zinc and not ferrous iron is enclosed in PPIX, is a by-product in living organisms, as FECH shows a strong specificity for ferrous iron above other divalent ions (Hunter et al. 2008). No studies could be found that describe initial concentrations of Zn(II)PPIX in muscle cells, but Labbé et al. (1999) reported trace amounts of Zn(II)PPIX and PPIX in erythroid cells of healthy persons. In case of iron deficiency or lead exposure, however, formation of Zn(II)PPIX increases (Jacobs et al. 1998; Labbé et al. 1999).

Also after cell death, Zn(II)PPIX tends to increase. Wakamatsu et al. (2004a) identified $\mathrm{Zn}(\mathrm{II}) \mathrm{PPIX}$ as the main pigment in Italian dry cured Parma hams. Later, Zn(II)PPIX formation was confirmed in several other studies focusing on production of nitrite-free (since nitric oxide (NO) inhibits FECH activity) meat products, such as dry cured Iberian hams and dry fermented sausages (Adamsen et al. 2006; De Maere et al. 2016). Since several years, researchers are interested to elucidate the formation mechanisms of $\mathrm{Zn}$ (II)PPIX in meat products as it could play an important role in colour formation without the addition of the controversial nitrite or nitrate, whereby nitrosylmyoglobin normally acts as main pigment. Although much is already known, not all mechanisms are unraveled yet, which limits further implementations in meat industry.

Schneider et al. (2008) and Durek et al. (2012) suggested to use the immediate increase of $\mathrm{Zn}(\mathrm{II}) \mathrm{PPIX}$ fluorescence after slaughtering as a quality indicator of fresh pork meat with regards to inadequate conditioning (e.g. during transportation and/or storage). In these studies, the contribution of FECH formed by bacteria or yeasts was suggested. Although differences in FECH activities between mammals, bacteria and yeast could be seen, and could be related to the presence of a $2 \mathrm{Fe}-2 \mathrm{~S}$ cluster which is present in mammalian FECH but not always in bacterial FECH (Daily et al. 2000; Chau et al. 2011), still much more investigation is needed 
to predict the impact of the involvement of microorganisms for the formation of $\mathrm{Zn}$ (II)PPIX in meat and meat products.

Enzymatic (endogenous or bacterial) and non-enzymatic Zn(II)PPIX formation pathways are already described, but it is very difficult to understand in vivo which pathway(s) are relevant in meat or meat products. Becker et al. (2012) suggested that in meat products enzymatic formation mainly occurs in the beginning of the processes and that non-enzymatic formation takes over when enzyme activity decreases. Nevertheless, parallel enzymatic and nonenzymatic formation is possible. Enzymatic formation includes a substitution reaction with FECH being responsible for both the removal of ferrous iron from PPIX and the insertion of zinc into PPIX (Chau et al. 2010). De novo Zn(II)PPIX formation without participation of heme, as described by Wakamatsu et al. (2007), was questioned by Chau et al. (2011) as they assumed that the biosynthesis pathway of heme is interrupted in fresh meat since no protoporphyrinogen oxidase, which catalizes the oxidation of protoporphyrinogen to PPIX (Aijoka et al. 2006), has been demonstrated yet. This enzyme is also known to be unstable after cell death (Chau et al. 2011).

In this study, the importance of some intrisic parameters in relation to in vitro formation of $\mathrm{Zn}(\mathrm{II}) \mathrm{PPIX}$ was investigated, namely $\mathrm{pH}$, water activity (aw), initial metmyoglobin formation (IMF), metmyoglobin reduction ability (MRA), total heme content, zinc chelatase activity and total iron and zinc concentration. Parolari et al. (2009) already related Zn(II)PPIX synthesis during maturation of Parma ham to the presence of residual zinc chelatase activity. They even hypothised that checking fresh meat for the enzyme content may be a means to control colour formation in nitrite-free meat products. The $\mathrm{pH}$ optima of $\mathrm{FECH}$ ranges from $\mathrm{pH} 5.5$ to 8.0 according to its origin and function (Chau et al. 2010; Ishikawa et al. 2006; Wakamatsu et al. 2007; Wakamatsu et al. 2015). Therefore, the ultimate $\mathrm{pH}$ of fresh meat is considered as a potentially important factor for FECHs ability to form $\mathrm{Zn}$ (II)PPIX. Little is known about the optimal aw values for $\mathrm{Zn}$ (II)PPIX formation, although formation occured in both fresh meat and dried meat products (Schneider et al. 2008; Wakamatsu et al. 2004a). In fresh meat, myoglobin oxidizes easily to form metmyoglobin (MMb). Prior to the removal of ferrous iron from heme and the insertion of zinc ions to form $\mathrm{Zn}$ (II)PPIX by FECH, reduction of hemin is necessary (Chau et al. 2010; Hunter et al. 2008). Therefore, it is postulated that significant differences in intrinsic reducing mechanisms between fresh meats could have an effect on endogenous $\mathrm{Zn}$ (II)PPIX formation. Finally, heme is considered as the substrate for $\mathrm{Zn}$ (II)PPIX formation (Chau et al. 2011) and also an influence of iron and zinc is not 
inconceivable. Ferrous iron is a strong inhibitor of zinc insertion, thus it is often assumed that $\mathrm{Zn}$ (II)PPIX is merely formed in meat products when iron availability decreases (Becker et al. 2012; Grossi et al. 2014). Zinc is also present in meat in relatively high amounts (Devine et al. 2004). It is assumed that a higher concentration of zinc may promote $\mathrm{Zn}(\mathrm{II}) \mathrm{PPIX}$ formation, however, it has been shown that the profit of extra zinc addition is limited as it acts as a substrate inhibitor of mammalian FECH (Becker et al. 2012; Hunter et al. 2008).

Until now, mainly pork meat has been used to evaluate the formation of $\mathrm{Zn}$ (II)PPIX (Adamsen et al. 2006; Durek et al. 2012; Schneider et al. 2008; Wakamatsu et al. 2004a). Also porcine liver tissue is known to be a good source for $\mathrm{Zn}$ (II)PPIX formation (Chau et al. 2010; Wakamatsu et al. 2015). Other studies used extracted porcine heart mitochondria (Ishikawa et al. 2007). Comparison with meat sources other than pork, however, could reveal additional information for a better understanding of the formation mechanisms of $\mathrm{Zn}$ (II)PPIX in meat or for establishing the production of nitrite-free meat products other than dry cured pork hams.

The aim of this study was to evaluate endogenous enzymatic Zn(II)PPIX formation in different meat sources and to relate this formation to the potentially important intrinsic parameters discussed above. Specifically, this study presents the screening of eight different meat sources, namely chicken, turkey, pork, lamb, beef, veal, horse and liver, on eight intrinsic parameters possibly important for the formation of Zn(II)PPIX. Additionally, for each meat source the potential for Zn(II)PPIX formation was estimated. To this end, a meatbased in vitro model was established with the addition of antibiotics to exclude the influence of microorganisms and to focus on the endogenous enzymatic pathway of $\mathrm{Zn}$ (II)PPIX formation. Using Partial Least Squares Regression (PLS) analysis, the in vitro Zn(II)PPIX formation was related to the intrinsic parameters screened in order to identify their relative importance. 


\section{Materials and methods}

\subsection{Meat samples}

Meat (250 g) originating from the shoulder or wing (m. Triceps brachii) of chicken, turkey, pork, lamb, beef, veal, horse, and porcine liver were purchased from a local butcher, each at three different randomly chosen times during a period of 6 months. Within 48 hours after slaughter the meat samples were collected and partly used for immediate analysis of $\mathrm{pH}$, aw, dry matter (DM), IMF and MRA. Other parts of the samples were frozen at $-24{ }^{\circ} \mathrm{C}$ until quantitative analysis was performed of zinc chelatase activity, total heme, PPIX, Zn(II)PPIX, total iron and zinc. In addition, frozen and thawed meat was used in the in vitro models applied for assessment of PPIX and Zn(II)PPIX formation. All analyses were performed in triplicate.

\subsection{Assessment of potentially important intrinsic parameters for the formation of zinc protoporphyrin IX}

\subsubsection{Physico-chemical analysis}

The $\mathrm{pH}$ in the meat samples was measured by inserting the glass $\mathrm{pH}$ electrode in the meat portion (Knick Portamess ${ }^{\mathrm{G}}$, Houston, USA). Aw of minced meat portions was determined using a dewpoint hygrometer (AquaLab, Decagon Devices, Pullman, USA).

\subsubsection{Initial metmyoglobin formation and metmyoglobin reducing ability}

The methodology used for determining MRA of meat differs widely among researchers. But after comparing different assays in beef, Samel et al. (2002) concluded that the reduction of $\mathrm{NO}$-induced $\mathrm{MMb}$ offered a good practical approach for determining MRA. This method was described in AMSA Meat Colour Measurement Guide (2012) and was applied in this study. AMSA, however, recommends evaluating additionally also the initial $\mathrm{MMb}$ formation induced by NO, as it is also considered as a good indicator of sample MRA (see also Mancini et al. 2008).

Summarized, after removing all visible fat and connective tissue, samples of $3 \times 3 \times 2 \mathrm{~cm}$ were prepared. Initially, the surface pigments of the samples were oxidized to MMb by soaking them in a $0.3 \%(\mathrm{w} / \mathrm{w})$ sodium nitrite solution for 20 minutes at room temperature. Then, the samples were vacuum packed (PA/PE 20/70, $50 \mathrm{~cm}^{3}$ oxygen/ $\mathrm{m}^{2}$.d.bar at $23{ }^{\circ} \mathrm{C} / 0 \%$ relative humidity, Imagopack, Deerlijk, Belgium) and reflectance was scanned going from 400 to $700 \mathrm{~nm}$ before and after 2 hours incubation at $30{ }^{\circ} \mathrm{C}$. Therefore, a Miniscan EZ 4500L 
$45^{\circ} / 0^{\circ}$ (Hunterlab, Murnau, Germany) with $8 \mathrm{~mm}$ viewing area size, illuminant D65 and $10^{\circ}$ standard observer was used. Via selected wavelengths of the obtained reflectance spectra, surface MMb (\%) was calculated before and after incubation. IMF (\%) is the initial MMb formation induced by $\mathrm{NO}$ before incubation and reflects the resistance of meat to $\mathrm{MMb}$ formation. MRA (\%) is defined as the percentage decrease in surface MMb concentration during the incubation period. The decline in MMb is assumed to reflect the tissue's ability to reduce ferric heme iron.

\subsubsection{Total heme content}

Total heme content was determined based on the method described by Lombardi-Boccia et al. (2002) with minor modifications, whereby an acidified acetone solution was used to extract heme from all heme proteins in the form of hemin. Minced meat samples $(4.00 \mathrm{~g})$ were weighted in a centrifuge tube with the addition of $25 \mathrm{~mL} 75 \% \mathrm{v} / \mathrm{v}$ acidified acetone solution $(3.15 \% \mathrm{v} / \mathrm{v} \mathrm{HCl})$. The mixture was subsequently vigorously mixed for 5 minutes using an ultra-turrax T25 homogenizer (IKA ${ }^{\circledR}$, Staufen, Germany), continuously shaken for 1 hour (nutating mixer, VWR International, West Chester, PA, USA), centrifuged for 10 minutes at $557 \times g$ and filtered through filter paper (Machery-Nagel MN 616, Filter Service, Eupen, Belgium). Absorbances were measured at $640 \mathrm{~nm}$ via spectrophotometry (Cary 100 Bio, Agilent Technologies, CA, US). Concentrations were calculated using calibration curves of meat samples spiked with hemin (Sigma Aldrich, Diegem, Belgium). Data are expressed as $\mathrm{nmol} / \mathrm{g}$ DM, with DM (\%) determined by drying a homogenized test portion to constant mass at $103{ }^{\circ} \mathrm{C}$ (ISO 1442, 1997). All reagents were appropriate for analytical use.

\subsubsection{Zinc chelatase activity}

Zinc chelatase activity was determined based on the method described by Parolari et al. (2009) with minor modifications. Summarised, $1.00 \mathrm{~g}$ trimmed ground muscle was accurately weighted in a centrifuge tube and homogenized (ultra-turrax T25, IKA ${ }^{\circledR}$ ) for 2 minutes in $25 \mathrm{~mL}$ of ice cold extraction buffer containing tris- $\mathrm{HCl} 20 \mathrm{mM}$, glycerol $20 \%$ (w/v), $\mathrm{KCl}$ $0.8 \%(\mathrm{w} / \mathrm{v})$ and Triton X100 1\% (w/v). The homogenate was subsequently stored for 30 minutes at $4{ }^{\circ} \mathrm{C}$, centrifuged at $15000 \times g$ for 10 minutes and filtered through filter paper $\left(\mathrm{S} \& \mathrm{~S}^{\circledR}\right.$ 597, Sigma Aldrich). The crude muscle extract was stored at $4{ }^{\circ} \mathrm{C}$.

For the zinc chelatase activity assay, the muscle extract $(250 \mu \mathrm{L})$ was incubated at $37{ }^{\circ} \mathrm{C}$ for 45 minutes in the dark with $125 \mu \mathrm{L}$ of $400 \mu \mathrm{M} \mathrm{ZnSO} 4$ in $360 \mathrm{mM}$ Tris- $\mathrm{HCl}$ buffer (pH 7.0), $25 \mu \mathrm{L}$ of $0.25 \mathrm{mM}$ PPIX in Tris-HCl buffer $(\mathrm{pH}=7), 100 \mu \mathrm{L}$ of $25 \mathrm{mM}$ ATP solution in $\mathrm{NaCl}$ 
$20 \%(\mathrm{w} / \mathrm{v}) \mathrm{H} 2 \mathrm{O}$. Each extract was assayed against a blank obtained by adding $17.5 \mu \mathrm{L}$ of $50 \mathrm{mM}$ EDTA to the reaction mixture. After incubation, the enzymatic reaction was stopped by adding $17.5 \mu \mathrm{L}$ of EDTA and $0.5 \mathrm{~mL}$ of ethanol $96 \%(\mathrm{v} / \mathrm{v})$. The resulting solutions were centrifuged at $26000 \times g$ for 10 minutes. Finally, the clear supernatants was submitted to fluorescence analysis using a Fluoroskan Ascent FL Microplate Fluorometer type 374 (Thermo Scientific, Waltham, US) with an excitation filter of $420 \mathrm{~nm}$ and an emission filter of $590 \mathrm{~nm} . \mathrm{Zn}$ (II)PPIX (Sigma Aldrich) was used as standard. Data are expressed as nmol/g DM per minute. All reagents were appropriate for analytical use.

\subsubsection{Total iron and zinc content}

For the determination of total iron and zinc, aliquots of $4.00 \mathrm{~g}$ were weighted in stone crucibles, preliminarily rinsed with concentrated hydrochloric acid $(37 \% \mathrm{w} / \mathrm{w})$. The crucibles were subsequently heated for 2 hours at $103{ }^{\circ} \mathrm{C}$, burned above direct flames and ashed at $500{ }^{\circ} \mathrm{C}$ (Nabertherm, Lilienthal, Germany) until a white/ grey colour. After cooling in a desiccator, the ashes were transferred into a $50 \mathrm{~mL}$ bowl and diluted with $0.05 \mathrm{M}$ nitric acid. Analyses were performed by an atomic absorption spectrometer (AAS, Solaar Unicam 989, Thermo Scientific) at a wavelength of $248.3 \mathrm{~nm}$ and $213.9 \mathrm{~nm}$ for the determination of total iron and total zinc, respectively. Concentrations, expressed as nmol/g DM, were estimated by standard addition with the use of iron and zinc standards (VWR International). All reagents were appropriate for analytical use.

\subsection{Zinc protoporphyrin IX and protoporphyrin IX formation using meat-based in vitro models}

\subsubsection{Initial protoporphyrin IX and zinc protoporphyrin IX content}

After thawing and mincing, meat samples $(1.00 \mathrm{~g})$ were accurately weighted into centrifuge tubes. Extraction was carried out by adding 5 volumes of $75 \% \mathrm{v} / \mathrm{v}$ acetone solution and homogenizing for 1 minute with an ultra-turrax T18 homogenizer (IKA ${ }^{\circledR}$ ). The meat samples were centrifuged for 5 minutes at $2697 \times g$. The extraction procedure was repeated 5 times. After each extraction the supernatant was filtered, all supernatants were pooled into dark volumetric flasks and then diluted up to $25 \mathrm{~mL}$ with the extraction solvent. Finally, the supernatants were transferred into dark vials carrying out a last filtration using syringe filters with $0.20 \mu \mathrm{m}$ pore size (Machery-Nagel Cromafil ${ }^{\mathbb{G}}$ RC-20/15 MS, Filter Service). During all extraction operations, direct contact with light was avoided as practical feasable. 
The chromatographic method was based on Wakamatsu et al. (2009) with some modifications. The fluorescence properties of PPIX (ex./em. 410/630 nm) and Zn(II)PPIX (ex./em. 420/590 nm) were used for their determination, using a Hitachi LaChrom Elite ${ }^{\mathrm{E}}$ high performance liquid chromatograph (HPLC) equipped with a model L2485 fluorescence detector (VWR International). The porphyrins were separated by isocratic elution with methanol/ ammonium acetate $(80: 20, \mathrm{v} / \mathrm{v}, \mathrm{pH}=5.16)$ as mobile phase at a flow rate of $1 \mathrm{~mL} /$ min at $35^{\circ} \mathrm{C}$ using an Altima ${ }^{\mathrm{TM}} \mathrm{C} 185 \mu \mathrm{m}, 150 \mathrm{~mm} \times 4.6 \mathrm{~mm}$ chromatographic column (Grace Davision Discovery Sciences, Lokeren, Belgium). A volume of $40 \mu \mathrm{L}$ of each sample was injected. PPIX and Zn(II)PPIX (Sigma Aldrich) were used as standards. Data are expressed as nmol/g DM. All reagents were appropriate for analytical use.

\subsubsection{Zinc protoporphyrin IX and protoporphyrin IX formation using meat-based in vitro models}

Wakamatsu et al. (2004b) established an experimental model system to elucidate the mechanisms through which $\mathrm{Zn}$ (II)PPIX is formed in meat. Based on their findings, also for this study a meat-based model system was constructed to determine the formation of $\mathrm{Zn}$ (II)PPIX and PPIX. Meat homogenates were prepared by homogenizing $20.0 \mathrm{~g}$ of meat (ultra-turrax T25, IKA ${ }^{\circledR}$ ) with 2 volumes of sterilised distilled water. After dividing the meat homogenates into centrifuge tubes (final meat concentrations of $2.74 \%$ ), a mix of antibiotics was added to the model to final concentrations of $897 \mathrm{U} / \mathrm{mL}$ for penicillin $\mathrm{G}$ potassium, $897 \mu \mathrm{g} / \mathrm{mL}$ for streptomycin sulphate, $449 \mu \mathrm{g} / \mathrm{mL}$ for gentamicin sulphate and $897 \mu \mathrm{g} / \mathrm{mL}$ for amphotericin B (Sigma-Aldrich). The test tubes with the solutions were put into an anaerobic jar and were incubated at $26^{\circ} \mathrm{C}$ for 7 days. Anaerobic conditions were achieved by adding an anaerobic gas generator, AnaeroGen $2.5 \mathrm{~L}$, accompanied by an anaerobic indicator into the jar (Oxoid, Basingstoke, UK).

Both on day 0 and day 7, a sample was taken from each solution. Samples were analysed for Zn(II)PPIX and PPIX in triplicate using HPLC as described above, but applying an adjusted extraction method. In this case, $3.00 \mathrm{~mL}$ of $100 \%$ acetone was added to $1.00 \mathrm{~mL}$ of solution to achieve a $75 \%$ acetone solution, which was homogenized for 1 minute (ultra-turrax T18, $\mathrm{IKA}^{\circledR}$ ). The sample was centrifuged for 5 minutes at $2697 \mathrm{~g}$. This extraction was repeated once with addition of $5.00 \mathrm{~mL}$ of $75 \% \mathrm{v} / \mathrm{v}$ acetone solution. After each extraction the supernatant was filtered and collected into dark volumetric flasks. The resulting volume was diluted up to $10 \mathrm{~mL}$ with $75 \% \mathrm{v} / \mathrm{v}$ acetone solution. The obtained solution was filtered by a syringe filter with $0.20 \mu \mathrm{m}$ pore size (Machery-Nagel Cromafil ${ }^{\mathrm{G}}$ RC-20/15 MS) and was 
transferred into dark vials. Also for this procedure, direct contact with light was avoided as much as possible to minimize degradation.

Additionally, $\mathrm{pH}$ was measured and the microbial count was analysed before and after incubation. The $\mathrm{pH}$ was measured by inserting the glass $\mathrm{pH}$ electrode in the sample portion $\left(\right.$ Knick Portamess $\left.^{\mathrm{G}}\right)$. Total aerobic count and Lactobacillus were determined by making dilutional series of the samples using sterile Ringer Solution (Ringer Solution 1/4 strength tablets, VWR International) and by inoculating them on Plate Count Agar (PCA) and de Man, Rogosa and Sharpe (MRS) plates, respectively (VWR International) using an Eddy Jet spiral plater (IUL Instruments, Barcelona, Spain). After inoculation, the PCA plates were incubated aerobically at $26^{\circ} \mathrm{C}$ for 48 hours, MRS plates anaerobically at $30^{\circ} \mathrm{C}$ for 72 hours. Microbial counts are expressed as the logarithm of colony-forming units per gram of meat (log cfu/g).

\subsection{Statistical analysis}

In the Figures, data are expressed as means \pm SE. Differences between meat sources according to intrinsic parameters ( $\mathrm{pH}, \mathrm{aw}, \mathrm{IMF}, \mathrm{MRA}$, total heme, total iron and zinc and zinc chelatase activity), initial Zn(II)PPIX and PPIX content and in vitro formation of Zn(II)PPIX and PPIX were determined by one-way analysis of variance (ANOVA) at a significance level of $P<0.05$ and using Tukey's post-hoc tests to account for multiple comparisons (IBM SPSS Statistics 21.0, Chicago, USA).

Partial Least square regression (PLS) analysis was performed for evaluating the influence of the intrinsic parameters on the in vitro formation of Zn(II)PPIX and PPIX using meat-based models (XLStat Base, Paris, France). 


\section{Results and discussion}

\subsection{Differences between meat sources for each potentially important intrinsic parameters}

for the formation of zinc protoporphyrin IX

\subsection{1. $\mathrm{pH}$ and water activity}

Results for $\mathrm{pH}$ and aw of the eight selected meat sources are shown in Fig. 1a and 1b, respectively. A significant difference $(P=0.000)$ in $\mathrm{pH}$ was found between the meat sources, with mean values going in increasing order from beef to veal, pork, horse, lamb, chicken, turkey and porcine liver. All measurements are situated within a range of $1.06 \mathrm{pH}$ units with $\mathrm{pH}$ values between 5.50 and 6.56 .

Various studies described already the post mortem $\mathrm{pH}$ decline in meat by anaerobic glycolysis with formation of lactic acid. The extend of this $\mathrm{pH}$ decline is dictated specifically by the glycogen content in the muscle at the time of exsangination, which differs from animal to animal, but also within an animal species and within muscle type (Devine et al. 2004). It is also generally known that stress related to slaughtering conditions affects the rate of $\mathrm{pH}$ decline as well as the ultimate $\mathrm{pH}$ reached (Lammens et al. 2007). The results obtained in this study correspond with data found in literature, whereby ultimate $\mathrm{pH}$ values of $5.5-5.6$ for beef (Devine et al. 2004), 5.6 - 5.7 for veal (Klont et al. 2000), 5.5 - 5.8 for pork (Devine et al. 2004), 5.7 - 5.8 for horse (Gill 2005; Litwinczuk et al. 2007), 6.0 and more for chicken and turkey (Chan et al. 2011; Devine et al. 2004) and 6.1 - 6.5 for fresh porcine liver (Jay et al. 2005) could be found.

In contrast to the $\mathrm{pH}$, no significant differences $(P=0.069)$ in aw could be observed between the different meat sources. A minimum value of 0.982 and a maximum value of 0.993 was obtained. Also in literature, aw values between 0.98 and 0.99 were reported for all fresh meats (Gurtler et al. 2014).

\subsubsection{Initial metmyoglobin formation and metmyoglobin reduction ability}

In Fig. 1c and 1d the mean values \pm SE of the IMF and MRA of the eight meat sources are shown, respectively. Significant differences in IMF $(P=0.000)$ and MRA $(P=0.000)$ between the different meat sources were seen. IMF was found to be around $40 \%$ for all meat sources. The only exception was chicken meat with IMF up to $60 \%$, indicating that chicken meat has clearly less resistance for MMb formation in comparison to the other meat sources. 
MRA increased going from liver, turkey, chicken, horse, veal, pork, lamb and beef, with values of only $12 \%$ for porcine liver but up to $30 \%$ for beef.

Elroy et al. (2015) found a significant effect of species on non-enzymatic MRA. The best reductions were seen in bovine, followed by equine and porcine myoglobins. Authors attributed this higher non-enzymatic MRA of bovine to the combined effect of more histidine residues in the myoglobin structure and a lower $\mathrm{pH}$. Earlier studies confirm that both enzymatic and non-enzymatic MRA occured better at lower $\mathrm{pH}$ values (Mikkelsen et al. 1999). However, Zhu and Brewer (1998) revealed that a too fast $\mathrm{pH}$ decline after slaughtering (linked to reduced pork quality) had the lowest MRA, resulting in rapid MMb accumulation and discolouration. The NO-induced MRA, assessed in this study, also revealed significant differences between different meat sources, with beef showing the highest mean value. Meat sources with higher MRA have better ability to reduce ferric heme iron. Moreover, relatively good correlations $(\mathrm{r}=-0.606)$ were seen between $\mathrm{pH}$ and MRA (see Table 1).

\subsubsection{Total heme concentration}

Fig. 1e shows the total heme content of the eight meat sources. Strong differences $(P=0.000)$ in total heme content were observed, ranging from $29.54 \mathrm{nmol} / \mathrm{g}$ DM to $3375.13 \mathrm{nmol} / \mathrm{g} \mathrm{DM}$ and resulting into four significantly different subgroups. Chicken, turkey and pork had the lowest amounts of total heme, whereas lamb meat was classified in a second subgroup and beef and veal showed similar amounts in a third subgroup. The highest total heme concentrations were obtained for horse meat and liver tissue. In this study, it was chosen to express all quantitative data in $\mathrm{nmol} / \mathrm{g}$ DM to allow an easy comparison of the corresponding fractions for each sample. In literature, however, heme concentrations are mostly expressed as $\mathrm{mg}$ heme iron/ $100 \mathrm{~g}$ fresh weight. Recalculated, this investigation revealed specific heme iron concentrations of $0.20 \pm 0.03,0.28 \pm 0.004,0.58 \pm 0.02,1.33 \pm 0.01,1.99 \pm 0.10,1.87 \pm 0.05$, $4.44 \pm 0.21$ and $4.55 \pm 0.23 \mathrm{mg} / 100 \mathrm{~g}$ fresh weight for chicken, turkey, pork, lamb, beef, veal and horse and liver, respectively.

Lombardi-Boccia et al. (2002) analysed total heme contents in different types of meat. Specifically, heme iron contents of $0.22 \pm 0.1,0.35 \pm 0.1,0.26 \pm 0.1,1.68 \pm 0.4,1.82 \pm 0.2$, $0.71 \pm 0.3,1.75 \pm 0.4 \mathrm{mg} / 100 \mathrm{~g}$ fresh weight were found for chicken, turkey, pork, lamb, beef, veal and horse, respectively. Estevez and Cava (2004) reported higher values of heme iron for pork meat, namely $5.72 \pm 0.78$ and $1.62 \pm 0.66 \mathrm{mg} / 100 \mathrm{~g}$ for Iberian and white pigs, respectively; the respective livers revealed heme iron contents of $10.07 \pm 3.75$ and $8.22 \pm$ 
$2.94 \mathrm{mg} / 100 \mathrm{~g}$. The main differences with our investigation are the higher results of heme iron for veal and horse and the lower results for liver. In previous studies (Cross et al. 2012; Estevez et al. 2004; Lombardi-Boccia et al. 2002; Warris et al. 1990) data of heme iron in meat and meat products varied markedly. According to Lombardi-Boccia et al. (2002) this was seen specifically for meats with high heme iron concentrations.

\subsubsection{Zinc chelatase activity}

In Fig. If the results for zinc chelatase activity of the eight meat sources are shown. The ability of FECH of different meat origins to insert zinc ions into the PPIX ring (and not the removal reaction of ferrous iron from PPIX) was analysed. The one-way ANOVA revealed significant differences $(P=0.000)$ in zinc chelatase activity between the eight meat sources, resulting in three different subgroups. Chicken, turkey and beef showed the lowest enzyme activity, followed by pork, lamb and veal. The activity of zinc chelatase was the highest for horse and porcine liver. Activities between $1.71 \mathrm{nmol} / \mathrm{g} \mathrm{DM} / \mathrm{min}$ and $123.81 \mathrm{nmol} / \mathrm{g} \mathrm{DM} /$ min were determined.

Parolari et al. (2009) showed zinc chelatase activities between $2.19 \pm 1.04$ and $7.18 \pm$ $3.27 \mathrm{nmol} / \mathrm{g} \mathrm{DM} / \mathrm{min}$ in green hams used for the processing of Parma ham, whereas in this study activities of $31.51 \pm 2.92 \mathrm{nmol} / \mathrm{g} \mathrm{DM} / \mathrm{min}$ in pork meat originating from the shoulder were found. Differences in zinc chelatase activities suggest different amounts of FECH in different mammalian tissues, Ishikawa et al. (2006) reported a 3.3-fold increase of zinc chelatase activity from light pork's loin to extremely dark porcine heart, or even between individual muscles belonging to the same cut (Parolari et al. 2009).

Since euchariotic FECH is located in the inner membrane of the mitochondria (Ferreira 1999), the presence of more mitochondria implies more activity of FECH and thus also more heme production. Indeed, very good correlations between total heme and zinc chelatase activity $(\mathrm{r}=$ 0.837) could be seen in this study (Table 1). In this respect, liver tissue and horse meat, known to contain high amounts of mitochondria, correspond with high contents of heme and strong zinc chelatase activities. Remarkable, however, is the significantly lower zinc chelatase activity in beef compared with pork, lamb and veal despite its relatively high heme content. Moreover, the zinc chelatase activity of beef equals those of chicken and poultry. The reason for this observation is unclear.

Mammalian FECH shares many common characteristics (Ishikawa et al. 2006). The amino acid sequence of porcine FECH showed high homology with bovine (91\%), human (85\%), 
mouse (87\%), and rat (76\%) equivalents (Chau et al. 2010). However, species-species differences were noted on selectivity of FECH to ferrous iron (Hunter et al. 2008), but also on sensitivity to inhibition by e.g. N-alkyl porphyrins, with human FECH being over 100 -fold more sensitive for N-methyl porphyrin than chicken FECH (Daily et al. 2000). Although researchers learned a lot about FECH the last decades, still much remains to be determined to estimate different activities between mammalian tissue types, such as the low zinc chelatase activity in beef in this study.

\subsubsection{Metal concentration}

Fig. $1 \mathrm{~g}$ and $1 \mathrm{~h}$ show the means $\pm \mathrm{SE}$ of the total iron and zinc content of the different meat sources, respectively. Strong differences $(P=0.000)$ between the different meat sources are observed. Increasing amounts of iron and zinc are seen going from chicken to turkey, pork, lamb, beef, veal, horse and liver, dividing them in different subgroups. A minimum iron amount of $352.17 \mathrm{nmol} / \mathrm{g}$ DM and a maximum of $5483.23 \mathrm{nmol} / \mathrm{g}$ DM was detected. Zinc was present in concentrations between $562.12 \mathrm{nmol} / \mathrm{g} \mathrm{DM}$ and $6257.55 \mathrm{nmol} / \mathrm{g} \mathrm{DM}$.

A general overview of the nutritional values of different foods and food products in Belgium are provided by Nubel vzw. Total iron and zinc contents given by Nubel vzw correspond with the data obtained in this study (see Table 2), only a big difference in liver iron was seen. The reason for this is unknown.

A good correlation between total iron and heme $(r=0.846)$ could be seen. Higher amounts of iron also correspond with higher amounts of zinc $(r=0.753)$ (Table 1).

\subsection{In vitro formation of zinc protoporphyrin $I X$ and protoporphyrin $I X$ related to potentially important intrinsic parameters}

\subsubsection{Initial zinc protoporphyrin IX and protoporphyrin IX concentrations}

Zn(II)PPIX (Fig. 2a) and PPIX (Fig. 2b) are only present in trace amounts in the different fresh meat sources reaching maxima of $18.53 \mathrm{nmol} / \mathrm{g} \mathrm{DM}$ and $5.78 \mathrm{nmol} / \mathrm{g} \mathrm{DM}$ for Zn(II)PPIX and PPIX, respectively. Generally, a similar trend as for total heme can be observed for $\mathrm{Zn}$ (II)PPIX, with chicken meat showing the lowest initial Zn(II)PPIX amounts, beef, horse and liver the highest. However, although beef and veal contained similar total heme contents, the amount of $\mathrm{Zn}$ (II)PPIX in veal was lower than in beef. On the contrary, beef showed the lowest initial amounts of PPIX whereas the highest amounts were found in veal. To our knowledge, initial concentrations of Zn(II)PPIX and PPIX in meat have not been reported yet. 


\subsubsection{In vitro formation of zinc protoporphyrin IX and protoporphyrin IX}

The results of the formation of $\mathrm{Zn}$ (II)PPIX and PPIX of the eight meat sources assessed via meat-based in vitro models are shown in Fig. 3a and 3b, respectively. Due to the addition of antibiotics, the influence of microbiota was excluded (data not shown). Additionally, no differences in $\mathrm{pH}$ after incubation could be detected (data not shown). Zn(II)PPIX formation was very low or even nonexistent in some of the chicken meat samples. Slightly higher $\mathrm{Zn}(\mathrm{II})$ PPIX formation was seen for turkey, pork, lamb, beef and veal. But significantly higher $\mathrm{Zn}(\mathrm{II})$ PPIX formation was obtained when horse meat or liver tissue was used in the model. In liver tissue, even a maximum amount of $833.99 \mathrm{nmol} / \mathrm{g}$ DM was formed.

In nitrite-free dry cured or fermented meat products, based on pork meat, $\mathrm{Zn}$ (II)PPIX formation was proven to be possible but the amount formed and the corresponding colouring of the meat product could still be improved (Adamsen et al., 2006; De Maere et al., 2016; Parolari et al., 2009). The current study revealed that horse meat has great potential to form $\mathrm{Zn}($ II)PPIX. Therefore, the hypothesis could be stated that colour formation will be more easily obtained by Zn(II)PPIX in nitrite-free meat products based on horse meat instead of the mainly used pork meat. In case of dry fermented sausages, horse meat is already often used (Boulogne type). Therefore, production of a red coloured nitrite-free dry fermented sausage based on horse meat would be very interesting for the meat industry. The use of porcine liver in dry cured or fermented meat products, on the other hand, is technologically less feasible.

For PPIX, similar trends as seen for Zn(II)PPIX formation could be observed between the different meat sources, but less clear significances were obtained and the formation of PPIX did not exceed $2.12 \mathrm{nmol} / \mathrm{g} \mathrm{DM}$, which is extremely low. This suggests that during the incubation period, any formed PPIX could immediately react with zinc to obtain $\mathrm{Zn}$ (II)PPIX. The low zinc chelatase activities obtained in e.g. chicken in this study resulted in low Zn(II)PPIX formation, and not in an accumulation of PPIX. This suggests that the iron/ zinc substitution reaction from heme depends on FECH activity which depends in turn on the type of meat source. Here, PPIX is only an intermediate molecule in this reaction mechanism whereby it is assumed that no PPIX formation occured by e.g. de novo reactions or any other formation pathway.

\subsubsection{Partial Least Squares analysis to identify the relative importance of the selected intrinsic} parameters for the formation of $\mathrm{Zn}(\mathrm{II}) \mathrm{PPIX}$

The contribution of the analyzed intrinsic parameters ( $\mathrm{pH}$, IMF, MRA, total heme concentration, zinc chelatase activity and total iron and zinc concentrations) on the formation 
of $\mathrm{Zn}$ (II)PPIX and PPIX using in vitro models based on eight different meat sources was evaluated using PLS. The aw showed no significant differences $(P=0.690)$ between the different meat sources, thus was not included in the model.

PLS analysis revealed that $61.2 \%$ of the variation in $\mathrm{Zn}$ (II)PPIX formation of the different meat sources was explained by the intrinsic parameters, whereas only $38.6 \%$ of the information was represented for PPIX formation. The regression coefficients (Fig. 4a and 4b) and the correlation matrix (Table 1) of the PLS predictions indicated that zinc chelatase activity, followed by total heme and total iron and zinc, were the most important factors for the formation of $\mathrm{Zn}$ (II)PPIX and PPIX, whereas $\mathrm{pH}$, IMF and MRA were of minor significance. In the following, specifically the formation of $\mathrm{Zn}$ (II)PPIX is emphasized, since the PPIX formation was found to be very low, hence less relevant.

The variations in $\mathrm{Zn}$ (II)PPIX formation in the different meat sources are mainly explained by their zinc chelatase activity $(r=0.765)$. This means that more $\mathrm{Zn}(\mathrm{II}) \mathrm{PPIX}$ could be formed in meat sources with better zinc chelatase activities. Liver extracts were already used in earlier studies because of their better Zn(II)PPIX-forming abilities (Chau et al. 2010; Wakamatsu et al. 2015), but this study revealed that horse meat, with equal zinc chelatase activities as that of porcine liver, also showed good Zn(II)PPIX formation, although not as much as in liver tissue. The reason for this is unclear, but other intrinsic characteristics will play a role here. In all other meat sources, Zn(II)PPIX formation was very low, which can at least in part be attributed to their low zinc chelatase activity, especially in chicken, turkey and beef. The importance of zinc chelatase activity confirms that the endogenous enzymatic Zn(II)PPIX formation pathway occurs in meat, as was already suggested by Parolari et al. (2009). In vivo, however, Zn(II)PPIX formation depends on multiple factors, whereby the significance of this endogenous enzymatic formation should be investigated further.

As already mentioned, zinc chelatase activity is correlated with total heme and total iron, which explains their importance for estimating the formation of $\mathrm{Zn}(\mathrm{II}) \mathrm{PPIX}(\mathrm{r}=0.614$ and $\mathrm{r}=$ 0.518 , respectively). But also total zinc content shows a relatively good correlation with zinc chelatase activity $(r=0.661)$, and was found to be equally important as total iron and heme for the estimation of $\mathrm{Zn}$ (II)PPIX formation. It can easily be explained that a higher heme substrate concentration and higher zinc concentrations will result in a better formation of $\mathrm{Zn}(\mathrm{II}) \mathrm{PPIX}$. It is thought that $\mathrm{Zn}$ (II)PPIX could only be formed in case of a decreased iron availability, since ferrous iron is known to be a strong inhibitor of zinc insertion (Becker et al. 2012; Grossi et al. 2014; Hunter et al. 2008). In this study, however, total iron concentration 
reflect mainly the heme iron concentration $(r=0.846)$, whereby the ratio non heme iron/ heme iron is rather small. A higher ultimate $\mathrm{pH}$ of meat correspond with a higher ability to form $\mathrm{Zn}$ (II)PPIX, but a correlation coefficient of only $\mathrm{r}=0.508$ was obtained. Chau et al. (2010) found $\mathrm{pH}$ optima of $7.5-8.0$ for the insertion of zinc in porcine mitochondria, which could explain the positive correlation in this study. But lower $\mathrm{pH}$ optima $(5.5-6.0)$ for the removal reaction were obtained. Also in meat-based models, optima of 5.5 were found (Wakamatsu et al. 2007). Thus, the influence of $\mathrm{pH}$ on $\mathrm{Zn}$ (II)PPIX formation is not unambiguous, which makes it not an optimal parameter to predict the formation of $\mathrm{Zn}$ (II)PPIX in meat. IMF and MRA did not seem to be crucial to predict the formation of $\mathrm{Zn}(\mathrm{II}) \mathrm{PPIX}$ in this study $(\mathrm{r}=-0.336$ and $\mathrm{r}=-0.382$, respectively). Moreover, the negative correlation of MRA with the formation of Zn(II)PPIX could not be explained as it is assumed that reduction of ferric iron in $\mathrm{MMb}$ would promote $\mathrm{Zn}$ (II)PPIX formation.

As only $61.2 \%$ of the variation in Zn(II)PPIX formation of the different meat sources could be explained by the analyzed factors, other factors which were not included in this study, will play a role as well. More investigation is required to elucidate all influencing intrinsic parameters, e.g. other divalent metal ions, for the endogenous formation of $\mathrm{Zn}$ (II)PPIX in meat. 


\section{Conclusions}

Significant differences in intrinsic parameters potentially important for the formation of Zn(II)PPIX, namely pH, IMF, MRA, total heme content, total iron and zinc content and zinc chelatase activity, between eight meat sources were found. Aw was similar in all meat sources. Only trace amounts of Zn(II)PPIX and PPIX could initially be found in meat sources. To our knowledge, this has never been reported before. The highest in vitro $\mathrm{Zn}$ (II)PPIX formation was achieved in liver tissue, which was expected due to its higher amount of mitochondria. But also horse meat showed very good ability to form Zn(II)PPIX. PLS analysis revealed that zinc chelatase activity, prior to heme, iron and zinc content, was the most important factor to explain the variation in $\mathrm{Zn}$ (II)PPIX formation, confirming that the endogenous enzymatic $\mathrm{Zn}(\mathrm{II}) \mathrm{PPIX}$ formation pathway occurs in meat and that it is species-dependent. Nevertheless, its importance in in vivo circumstances should be investigated further. PPIX was of minor importance in comparison with Zn(II)PPIX formation, suggesting that it acts as an intermediate in the substitution reaction from heme to $\mathrm{Zn}$ (II)PPIX and that no relevant PPIX is formed de novo or otherwise.

Although an appropriate selection of potentially important parameters was made in this study, still other intrinsic parameters should be investigated to predict their importance concerning the formation of $\mathrm{Zn}$ (II)PPIX in meat. A better understanding of the formation mechanisms of $\mathrm{Zn}(\mathrm{II}) \mathrm{PPIX}$ in meat and more specific knowledge about the influence of some intrinsic parameters, e.g. other divalent metal ions, is important for the meat industry in the search for the production of red coloured, but nitrite-free meat products. In this respect, the use of horse meat, rather than liver tissue which is technologically less feasible, in nitrite-free applications could be considered. 


\section{References}

Adamsen, C. E., Møller, J. K. S., Laursen, K., Olsen, K., \& Skibsted, L. H. (2006). Znporphyrin formation in cured meat products: Effect of added salt and nitrite. Meat Science, 72(4), 672-679.

Ajioka, R. S., Phillips, J. D., \& Kushner, J. P. (2006). Biosynthesis of heme in mammals. Biochimica et Biophysica Acta, 1763(7), 723-736.

AMSA. (2012). AMSA Meat Color Measurement Guidelines Measurement.

Becker, E. M., Westermann, S., Hansson, M., \& Skibsted, L. H. (2012). Parallel enzymatic and non-enzymatic formation of zinc protoporphyrin IX in pork. Food Chemistry, 130(4), 832-840.

Belgische voedingsmiddelentabel, Nubel vzw, 5e editie (2010).

Chan, J. T. Y., Omana, D. A., \& Betti, M. (2011). Effect of ultimate $\mathrm{pH}$ and freezing on the biochemical properties of proteins in turkey breast meat. Food Chemistry, 127(1), 109117.

Chau, T. T., Ishigaki, M., Kataoka, T., \& Taketani, S. (2010). Porcine Ferrochelatase: The Relationship between Iron-Removal Reaction and the Conversion of Heme to ZnProtoporphyrin. Bioscience, Biotechnology, and Biochemistry, 74(7), 1415-1420.

Chau, T. T., Ishigaki, M., Kataoka, T., \& Taketani, S. (2011). Ferrochelatase catalyzes the formation of Zn-protoporphyrin of dry-cured ham via the conversion reaction from heme in meat. Journal of Agricultural and Food Chemistry, 59(22), 12238-12245.

Cross, A. A. J., Harnly, J. J. M., Ferrucci, L. M. L., Risch, A., Mayne, S. T., \& Sinha, R. (2012). Developing a heme iron database for meats according to meat type, cooking method and doneness level. Food and Nutrition Sciences, 3(7), 905-913.

Dailey, H. A., Dailey, T. A., Wu, C., Medlock, A. E., Wang, K., Rose, J. P., \& Wang, B. (2000). Ferrochelatase at the millennium: structures, mechanisms and [ $2 \mathrm{Fe}-2 \mathrm{~S}$ ] clusters. Cellular and Molecular Life Sciences, 57, 1909-1926.

De Maere, H., Fraeye, I., De Mey, E., Dewulf, L., Michiels, C., Paelinck, H., \& Chollet, S. (2016). Formation of naturally occurring pigments during the production of nitrite-free dry fermented sausages. Meat Science, 114, 1-7.

Devine, C., \& Dikeman, M. (2004). Encyclopedia of Meat Sciences ed. Elsevier Acad. Press, Oxford.

Durek, J., Bolling, J. S., Knorr, D., Schwägele, F., \& Schlüter, O. (2012). Effects of different storage conditions on quality related porphyrin fluorescence signatures of pork slices. Meat Science, 90(1), 252-258. 
Elroy, N. N., Rogers, J., Mafi, G. G., Van Overbeke, D. L., Hartson, S. D., \& Ramanathan, R. (2015). Species-specific effects on non-enzymatic metmyoglobin reduction in vitro. Meat Science, 105, 108-113.

Estévez, M., \& Cava, R. (2004). Lipid and protein oxidation, release of iron from heme molecule and colour deterioration during refrigerated storage of liver pâté. Meat Science, $68(4), 551-558$.

Ferreira, G. C. (1999). Ferrochelatase. The International Journal of Biochemistry \& Cell Biology, 31(10), 995-1000.

Gill, C. O. (2005). Safety and storage stability of horse meat for human consumption. Meat Science, 71(3), 506-513.

Grossi, A. B., do Nascimento, E. S. P., Cardoso, D. R., \& Skibsted, L. H. (2014). Proteolysis involvement in zinc-protoporphyrin IX formation during Parma ham maturation. Food Research International, 56, 252-259.

Gurtler, J. B., Doyle, M. P., \& Kornacki, J. L. (2014). The microbiological safety of spices and low-water activity foods and spices. Food Microbiology and Food Safety. New York: Springer Science.

Hunter, G. a, Sampson, M. P., \& Ferreira, G. C. (2008). Metal ion substrate inhibition of ferrochelatase. The Journal of Biological Chemistry, 283(35), 23685-23691.

International Organization for Standardization (1997). Determination of moisture content, ISO 1442:1997 standard.

Ishikawa, H., Kawabuchi, T., Kawakami, Y., Sato, M., Numata, M., \& Matsumoto, K. (2007). Formation of Zinc Protoporphyrin IX and Protoporphyrin IX from Oxymyoglobin in Porcine Heart Mitochondria. Food Science and Technology Research, 13(1), 85-88.

Ishikawa, H., Yoshihara, M., Baba, A., Kawabuchi, T., Sato, M., Numata, M., \& Matsumoto, K. (2006). Formation of Zinc Protoporphyrin IX from Myoglobin with Pork Loin Extract. Journal of the Faculty of Agriculture, 51(1), 93-97.

Jacobs, J. M., Sinclair, P. R., Sinclair, J. F., Gorman, N., Walton, H. S., Wood, S. G., \& Nichols, C. (1998). Formation of zinc protoporphyrin in cultured hepatocytes: effects of ferrochelatase inhibition, iron chelation or lead. Toxicology, 125(2-3), 95-105.

Jay, J. M., Loessner, M. J., \& Golden, D. A. (2005). Modern Food Microbiology (7th ed.). New York: Springer Science.

Klont, R. E., Barnier, V. M. H., Van Dijk, A., Smulders, F. J. M., Hoving-Bolink, A. H., Hulsegge, B., \& Eikelenboom, G. (2000). Effects of rate of pH fall, time of deboning, aging period, and their interaction on veal quality characteristics. Journal of Animal Science, 78(7), 1845-1851. 
Labbé, R. F., Vreman, H. J., \& Stevenson, D. K. (1999). Zinc protoporphyrin: A metabolite with a mission. Clinical Chemistry, 45(12), 2060-2072.

Lammens, V., Peeters, E., De Maere, H., De Mey, E., Paelinck, H., Leyten, J., \& Geers, R. (2007). A survey of pork quality in relation to pre-slaughter conditions, slaughterhouse facilities, and quality assurance. Meat Science, 75(3), 381-387.

Lindahl, G. (2005). Colour Characteristics of Fresh Pork. Doctor's dissertation.

Litwinczuk, A., Florek, M., Skalecki, P., \& Litwinczuk, Z. (2008). Chemical Composition and Physicochemical Properties of Horse Meat From the Longissimus. Journal of Muscle Foods, 19(3), 223-236.

Lombardi-Boccia, G., Martinez-Dominguez, B., \& Aguzzi, A. (2002). Total Heme and Nonheme Iron in Raw and Cooked Meats. Journal of Food Chemistry and Toxicology, 67(5), $1738-1741$.

Mancini, R. A., Seyfert, M., \& Hunt, M. C. (2008). Effects of data expression, sample location, and oxygen partial pressure on initial nitric oxide metmyoglobin formation and metmyoglobin-reducing-activity measurement in beef muscle. Meat Science, 79(2), 244251.

Mikkelsen, A., Juncher, D., \& Skibsted, L. H. (1999). Metmyoglobin reductase activity in porcine m. longissimus dorsi muscle. Meat Science, 51(2), 155-161.

Parolari, G., Benedini, R., \& Toscani, T. (2009). Color formation in nitrite-free dried hams as related to Zn-protoporphyrin IX and Zn-chelatase activity. Journal of Food Science, 74(6), 413-418.

Samel, L.M., Hunt, M.C., Kropf, D.H., Hachmeister, K.A., \& Johnson, D. E. (2002). Comparison of Assays for Metmyoglobin Reducing Ability in Beef Inside and Outside. Food Chemistry and Toxicology, 67(3), 978-984.

Schneider, J., Wulf, J., Surowsky, B., Schmidt, H., Schwägele, F., \& Schlüter, O. (2008). Fluorimetric detection of protoporphyrins as an indicator for quality monitoring of fresh intact pork meat. Meat Science, 80(4), 1320-1325.

Wakamatsu, J., Murakami, N., \& Nishimura, T. (2015). A comparative study of zinc protoporphyrin IX-forming properties of animal by-products as sources for improving the color of meat products. Animal Science Journal, 86, 547-552.

Wakamatsu, J., Nishimura, T., \& Hattori, A. (2004a). A Zn-porphyrin complex contributes to bright red color in Parma ham. Meat Science, 67(1), 95-100.

Wakamatsu, J., Odagiri, H., Nishimura, T., \& Hattori, A. (2009). Quantitative determination of $\mathrm{Zn}$ protoporphyrin IX, heme and protoporphyrin IX in Parma ham by HPLC. Meat Science, 82(1), 139-142. 
Wakamatsu, J., Okui, J., Hayashi, N., Nishimura, T., \& Hattori, A. (2007). Zn protoporphyrin IX is formed not from heme but from protoporphyrin IX. Meat Science, 77(4), 580-586.

Wakamatsu, J., Okui, J., Ikeda, Y., Nishimura, T., \& Hattori, A. (2004b). Establishment of a model experiment system to elucidate the mechanism by which $\mathrm{Zn}$-protoporphyrin IX is formed in nitrite-free dry-cured ham. Meat Science, 68(2), 313-317.

Warriss, P. D., Brown, S. N., Adams, S. J., \& Lowe, D. B. (1990). Variation in haem pigment concentration and colour in meat from British pigs. Meat Science, 28(4), 321-329.

Zhu, L. G., \& Brewer, M. S. (1998). Metmyoglobin Reducing Capacity of Fresh Normal, PSE, and DFD Pork During Retail Display, Journal of Food Science, 63(3), 390-393. 
Table 1 Correlation matrix between intrinsic parameters and in vitro zinc protoporphyrin IX and protoporphyrin IX formation $(n=24)$

\begin{tabular}{|c|c|c|c|c|c|c|c|c|c|}
\hline Variables & $\bar{a}$ & $\sum$ & $\underset{\Sigma}{\Sigma}$ & 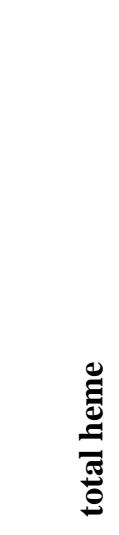 & 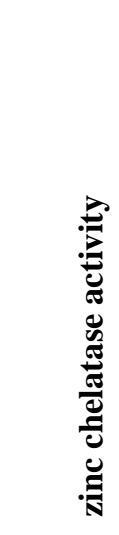 & 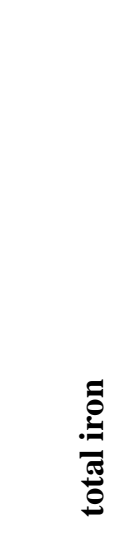 & 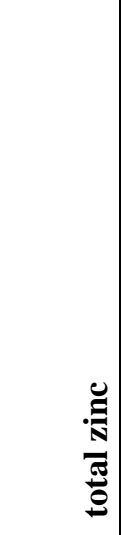 & 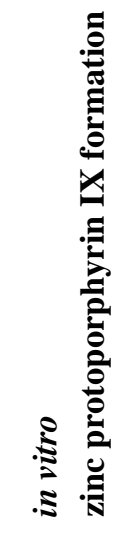 & 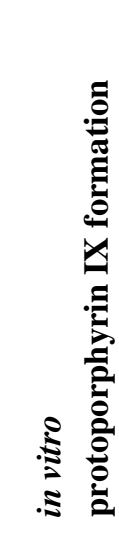 \\
\hline pH & 1.000 & -0.006 & -0.606 & 0.040 & 0.296 & 0.053 & -0.009 & 0.508 & 0.294 \\
\hline IMF & -0.006 & 1.000 & 0.149 & -0.330 & -0.397 & -0.312 & -0.423 & -0.336 & -0.421 \\
\hline MRA & -0.606 & 0.149 & 1.000 & -0.180 & -0.185 & -0.256 & -0.149 & -0.382 & -0.101 \\
\hline total heme & 0.040 & -0.330 & -0.180 & 1.000 & 0.837 & 0.846 & 0.768 & 0.614 & 0.456 \\
\hline zinc chelatase activity & 0.296 & -0.397 & -0.185 & 0.837 & 1.000 & 0.717 & 0.661 & 0.765 & 0.778 \\
\hline total iron & 0.053 & -0.312 & -0.256 & 0.846 & 0.717 & 1.000 & 0.753 & 0.518 & 0.422 \\
\hline total zinc & -0.009 & -0.423 & -0.149 & 0.768 & 0.661 & 0.753 & 1.000 & 0.602 & 0.314 \\
\hline $\begin{array}{l}\text { in vitro } \\
\text { zinc protoporphyrin IX formation }\end{array}$ & 0.508 & -0.336 & -0.382 & 0.614 & 0.765 & 0.518 & 0.602 & 1.000 & 0.614 \\
\hline $\begin{array}{l}\text { in vitro } \\
\text { protoporphyrin IX formation }\end{array}$ & 0.294 & -0.421 & -0.101 & 0.456 & 0.778 & 0.422 & 0.314 & 0.614 & 1.000 \\
\hline
\end{tabular}


Table 2 Total iron and total zinc content in different meat sources (Belgische voedingsmiddelentabel, Nubel vzw, 5e editie (2010) versus results obtained in this study)

\begin{tabular}{|c|c|c|c|c|c|c|c|c|c|}
\hline & & chicken & turkey & pork & lamb & beef & veal & horse & liver \\
\hline Nubel vzw Belgium & iron & 0.6 & 3.1 & 1.1 & 1.4 & 2.5 & 2.7 & 3.2 & 22.9 \\
\hline (mg/ 100g fresh weight) & zinc & 1.1 & 1.8 & 3.2 & 4.2 & 2.5 & 3.1 & 4.0 & 6.1 \\
\hline Results obtained in this study & iron & $1.5 \pm 0.3$ & $1.8 \pm 0.4$ & $1.8 \pm 0.2$ & $2.3 \pm 0.1$ & $2.7 \pm 0.2$ & $3.0 \pm 0.4$ & $4.5 \pm 0.2$ & $5.5 \pm 0.4$ \\
\hline (mg/ 100g fresh weight \pm SE) & zinc & $1.6 \pm 0.2$ & $2.7 \pm 0.3$ & $3.1 \pm 0.3$ & $4.3 \pm 0.3$ & $4.9 \pm 0.5$ & $5.3 \pm 0.2$ & $6.0 \pm 0.6$ & $6.7 \pm 0.6$ \\
\hline
\end{tabular}




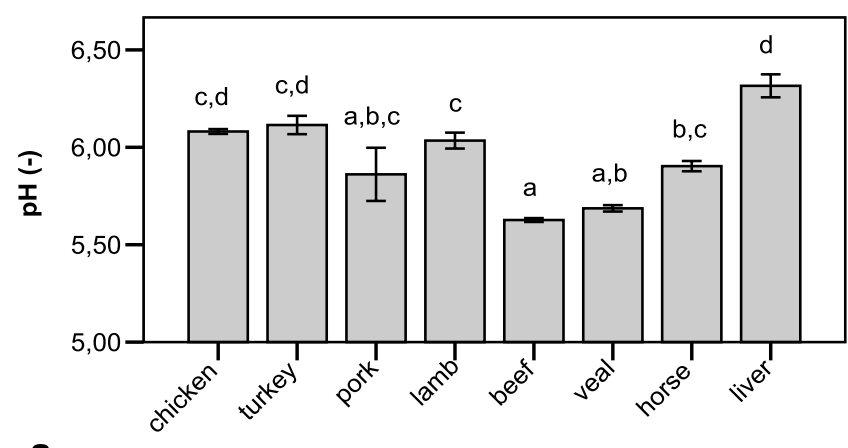

a

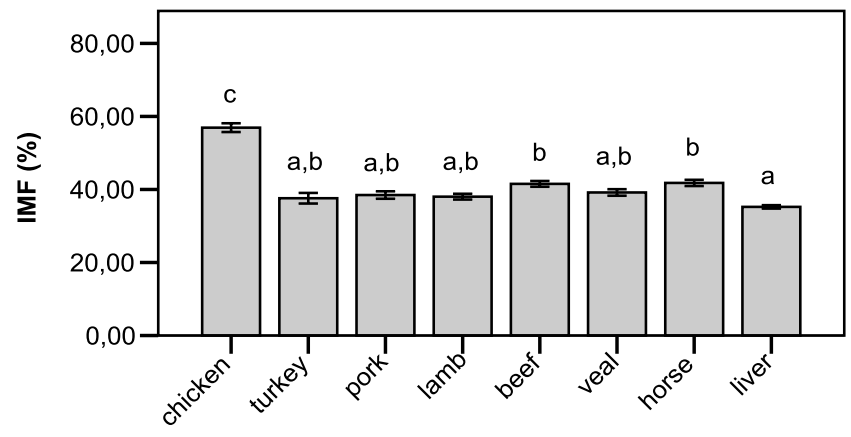

C

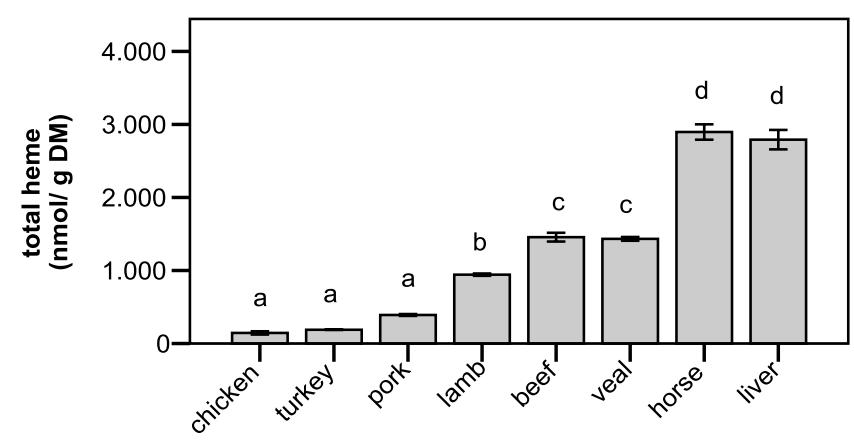

e

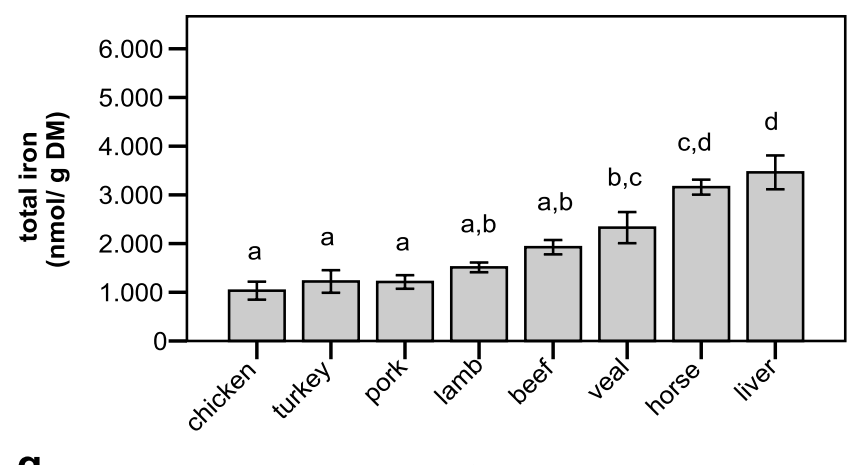

9

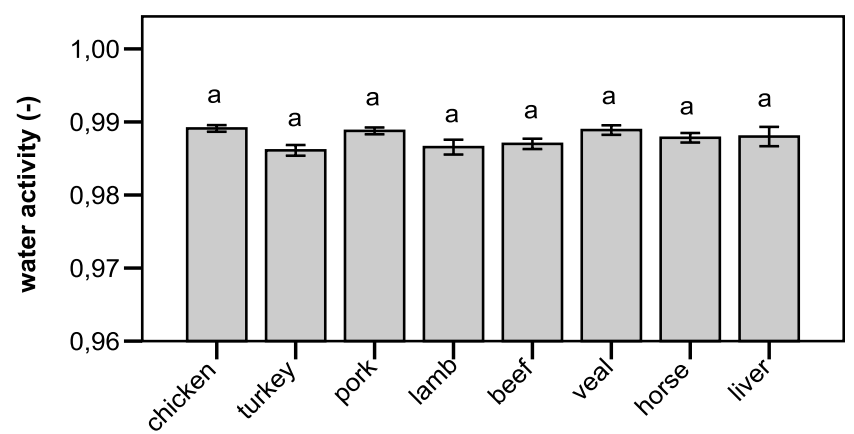

b

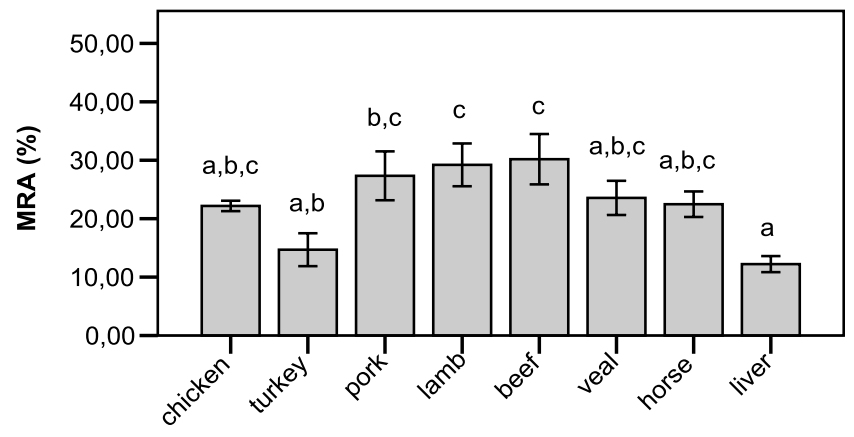

d

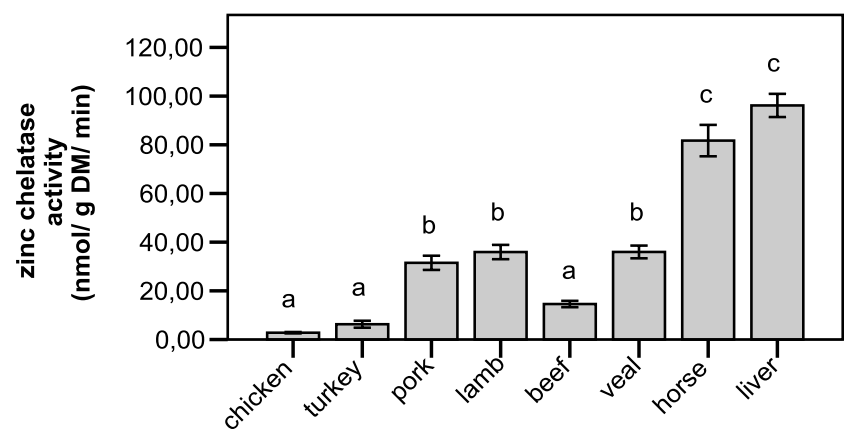

f

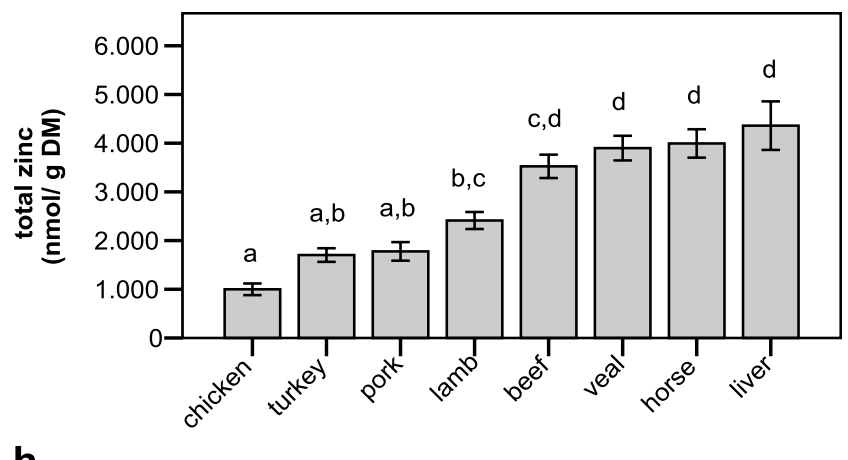

h

meat sources

Fig. 1 pH (a), water activity (b), initial metmyoglobin formation (c), metmyoglobin reduction ability (d), total heme content (e), zinc chelatase activity (f), total iron content (g) and total zinc content (h) of 8 meat sources, namely chicken, turkey, pork, lamb, beef, veal, horse and liver. Data are presented as means $\pm \mathrm{SE}(\mathrm{n}=9)$. Mean values indicated with the same letter are not significantly different based on Tukey's post hoc tests $(P<0.05)$. 

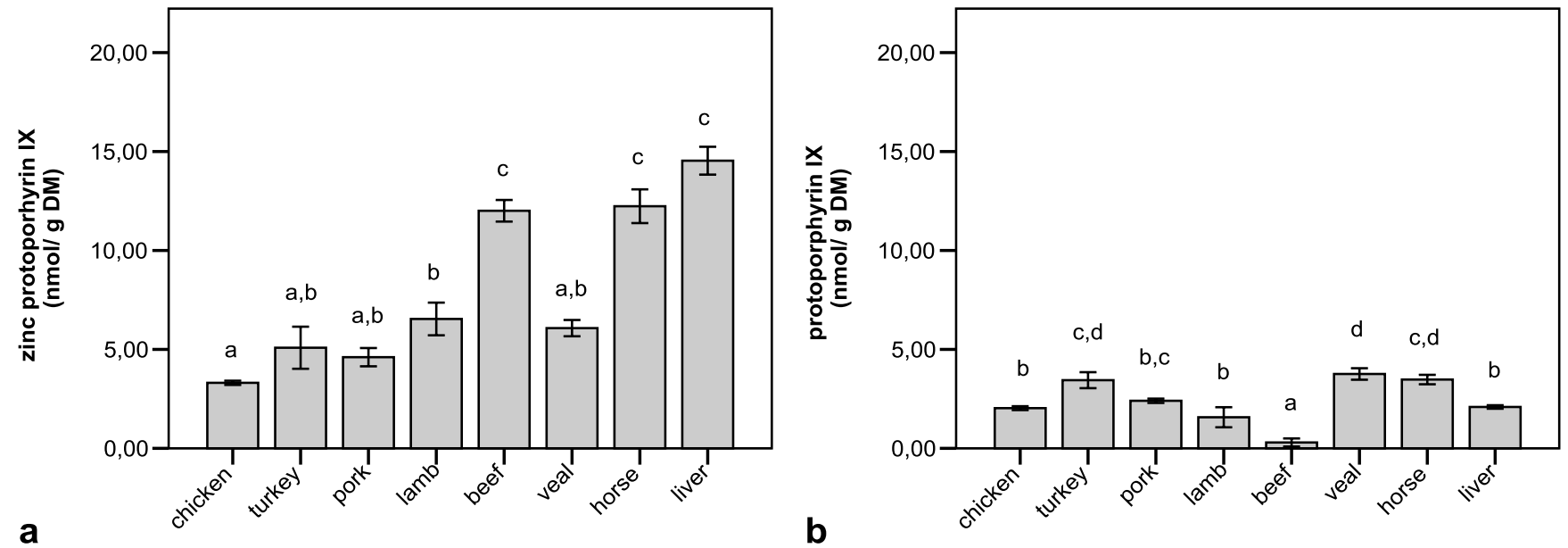

Fig. 2 initial zinc protoporphyrin IX (a) and protoporphyrin IX (b) content of 8 meat sources, namely chicken, turkey, pork, lamb, beef, veal, horse and liver. Data are presented as means $\pm \mathrm{SE}(\mathrm{n}=9)$. Mean values indicated with the same letter are not significantly different based on Tukey's post hoc tests $(P<0.05)$. 

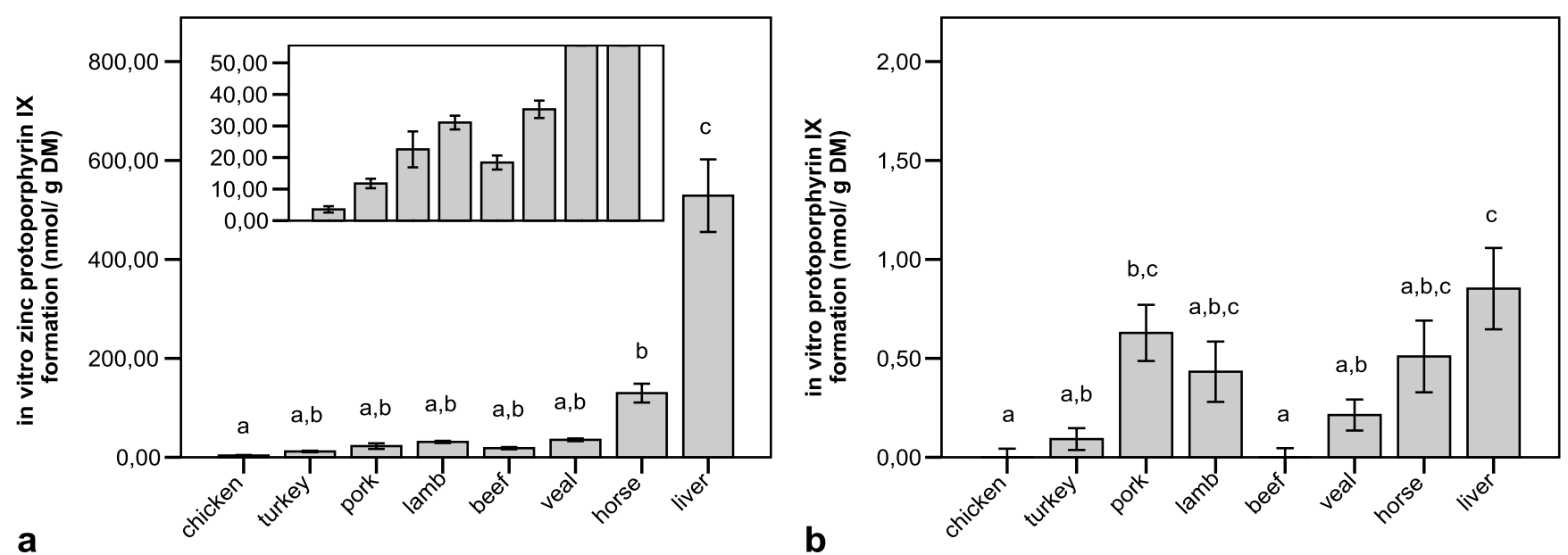

Fig. 3 in vitro formation of zinc protoporhyrin IX (a) and protoporphyrin IX (b) of 8 meat sources, namely chicken, turkey, pork, lamb, beef, veal, horse and liver. Data are presented as means \pm SE $(n=9)$. Mean values indicated with the same letter are not significantly different based on Tukey's post hoc tests $(P<0.05)$. 

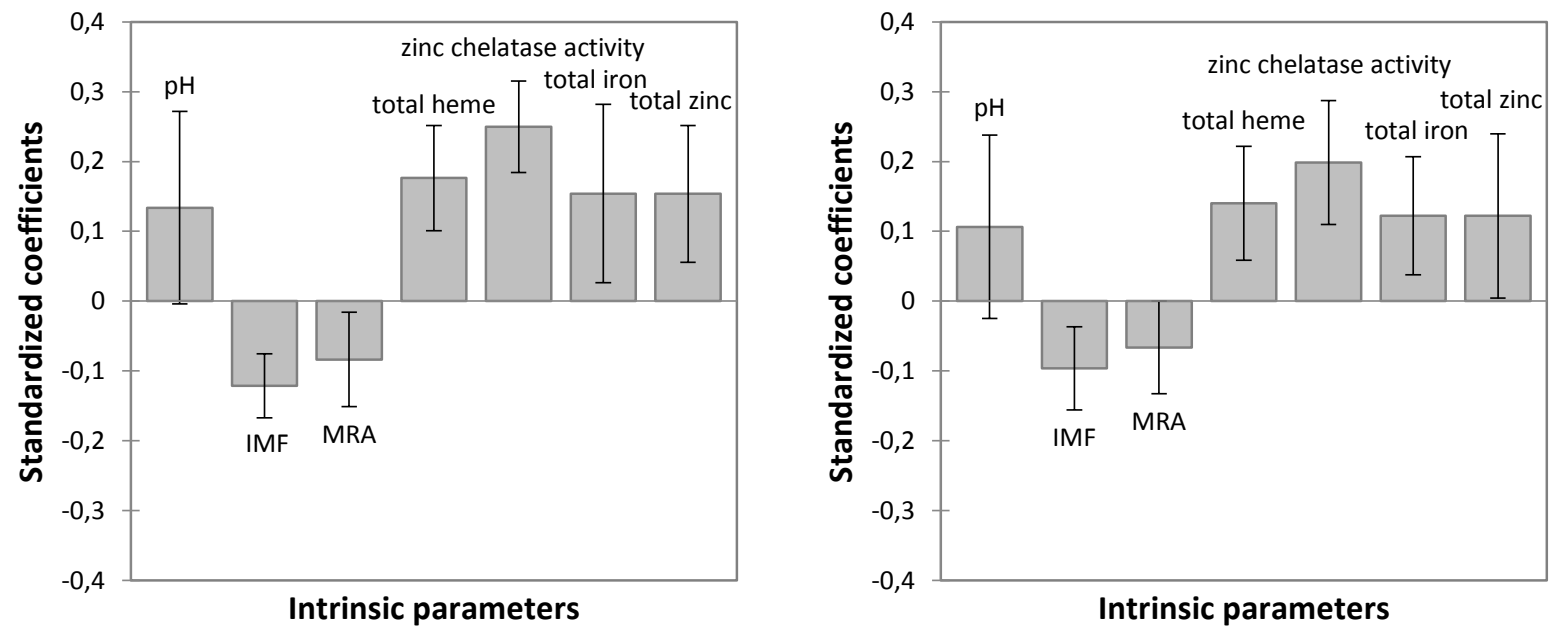

Fig. 4 Normalised coefficients (CI 95\%) for in vitro zinc protoporphyrin IX (a) and protoporphyrin IX formation (b) modelization assessed by Partial Least Squares regression analysis $(\mathbf{n}=\mathbf{2 4})$ 